\title{
A Society of General Internal Medicine Position Statement on the Internists' Role in Social Determinants of Health
}

\author{
Elena Byhoff ${ }^{7}$ (D), Shreya Kangovi, MD MSHP2, Seth A. Berkowitz, MD MPH ${ }^{3}$, \\ Matthew DeCamp, MD PhD ${ }^{4}$, Elizabeth Dzeng, MD MPH PhD ${ }^{5}$, Mark Earnest, MD PhD , \\ Cristina M. Gonzalez, MD MEd', Sarah Hartigan, MD', Reena Karani, MD MHPE ${ }^{8}$, \\ Milad Memari, MD ${ }^{9}$, Brita Roy, MD MPH MHS ${ }^{10}$, Mark D. Schwartz, MD ${ }^{11}$, \\ Anna Volerman, $\mathrm{MD}^{12}$, and Karen DeSalvo, MD MPH ${ }^{13}$ On behalf of the Society of \\ General Internal Medicine
}

\begin{abstract}
'Department of Medicine, Institute for Clinical Research and Health Policy Studies Tufts Medical Center, Tufts University School of Medicine Boston, MA, USA; ${ }^{2}$ Department of Medicine, University of PennsylvaniaPhiladelphia, PA, USA; ${ }^{3}$ Department of Medicine, University of North CarolinaChapel Hill, NC, USA; ${ }^{4}$ Department of Medicine, University of ColoradoAurora, CO, USA; ${ }^{5}$ Department of Medicine, University of CaliforniaSan Francisco, CA, USA; ' Department of Medicine, Albert Einstein College of Medicine, Montefiore Medical CenterBronx, NY, USA; ${ }^{7}$ Department of Medicine, Virginia Commonwealth UniversityMidlothian, VA, USA; ${ }^{8}$ Department of Medicine, Medicine and Geriatrics and Palliative Medicine lcahn School of Medicine at Mount SinaiNew York, NY, USA; ${ }^{9}$ Departments of Medical Education, Johns Hopkins University School of MedicineBaltimore, MD, USA; ${ }^{10}$ Department of Medicine, Yale MedicineNew Haven, CT, USA; " ${ }^{1}$ Departments of Population Health and of Medicine, NYU Grossman School of MedicineNew York, NY, USA; ${ }^{2}$ Department of Medicine, University of ChicagoChicago, IL, USA; ${ }^{13}$ GoogleMountain View, CA, USA.
\end{abstract}

J Gen Intern Med 35(9):272 1-7

DOI: $10.1007 / \mathrm{s} 11606-020-05934-8$

(c) The Author(s) 2020. This article is an open access publication

For if medicine is really to accomplish its great task, it must intervene in political and social life. It must point out the hindrances that impede the normal social functioning of vital processes, and effect their removal.

-Rudolf Virchow, 1849.

The Society of General Internal Medicine (SGIM) represents the world's leading academic general internists, dedicated to creating a just system of care in which all people can achieve optimal health. SGIM recognizes that to achieve this vision, we must expand our reach beyond the medical office and hospital bedside to identify and address the broader structures and living conditions that influence health - the social determinants of health (SDOH). Centuries of institutionalized oppression in the form of racism, sexism, and other forms of bigotry have created and perpetuated disadvantage. These underlying social values have translated into public policies and structures which affect the distribution of money and power across society. These in turn have shaped living conditions and access to resources, which influence health behaviors and access to care, and ultimately health outcomes. ${ }^{1,2}$ SGIM acknowledges the full spectrum of SDOH including upstream policies, midstream environmental and behavioral factors, and downstream

Received April 30, 2020

Accepted May 18, 2020

Published online June 9, 2020 individual and clinical issues. ${ }^{3-5}$ We highlight an important distinction between societal SDOH that require policy and systems-level change, with downstream unmet individual social needs, like homelessness or food insecurity. The entire range of SDOH impacts the work we do, our ability to care for our individual patients, our partnerships with local community organizations, and our impact on population health and equity. SDOH should also be integrated in how we teach future physicians and collaborate with our colleagues in public health, social work, government, research, and partners in non-health sectors.

In this position statement, we draw from medicine, public health, sociology, and ethics to contextualize the daily relevance of upstream $\mathrm{SDOH}$ and downstream social risks for SGIM members. We support statements issued by the American College of Physicians, the American Academy of Pediatrics, the National Academy of Medicine, and others. ${ }^{6-8} \mathrm{We}$ build upon these to offer a set of positions specifically tailored for the academic general internist. SGIM members are practicing physicians, health system leaders, educators, researchers, and advocates. We articulate strategies for how each of these roles can be leveraged to address $\mathrm{SDOH}$ and social needs, and ultimately to improve health and health equity.

\section{A CASE STUDY}

A 67-year-old woman with hypertension presents, complaining of dizziness. She was in the office a month earlier with the same complaint. At that visit, her blood pressure was $118 / 62$, a bit lower than usual. She stopped one of her blood pressure medications as instructed, but her symptoms persisted. The dizziness interferes with her work as a store cashier. An EKG and complete physical exam fail to 
explain her dizziness. You ask her to share more about her symptoms. She tells you her daughter and grandchildren recently moved back in with her after their rent was raised. Money is tight. The local food pantry is only open one day a week, and often the line is so long that she cannot afford to wait and miss work. She has cut back on meals. Her landlord has discovered that she has new family members living in the unit who are not on the lease and is threatening eviction.

Her physician is witness to the impact of upstream $\mathrm{SDOH}$ on her clinical presentation. Generations of unjust policies created these downstream effects: 50 years ago, she was unable to buy a home in desirable neighborhoods as a result of federal redlining policies restricting "negroes or foreigners" from buying homes in A-rated neighborhoods. ${ }^{9}$ Her current community-its school systems, food stores, and transit hubs-suffered decades of disinvestment. Her financial challenges result from a scarcity of well-paying jobs, cliff effects for benefits like the supplementary nutrition assistance programs and Section 8 housing, and regressive economic policies that tie social security to lifetime earnings. The cumulative effects of these stressors she's experiencing, combined with structural and institutional gender and racial bias, contribute to her increased risk of poor health outcomes.

While the evidence is clear that these SDOH and social needs directly impact health, the doctor's role has been less well-defined. The time has come to define our role. As illustrated in this vignette, poor health and health inequity are the consequence of multiple complex and intersecting problems. Thus, we propose countervailing actions across our spheres of influence as physicians, health system leaders, educators, researchers, and advocates.

\section{EXECUTIVE SUMMARY: ACTION ACROSS OUR SPHERES OF INFLUENCE}

SGIM as an organization and its members should and will commit to the following positions:

- As practicing physicians, we should learn about our patients as people through relationship-centered communication and self-reflection about how our own biases might interfere with our ability to deliver equitable care. We should hire and work in interprofessional care teams to ensure we can provide whole-person care to our patients. Interprofessional teams should include social care specialists such as community health workers or peer navigators to integrate medical and social aspects for whole-person care, as well as the expertise of nurses, pharmacists, mental health providers, and others.

- As health system leaders, we should encourage our organizations to partner with community members and community-based organizations. Our health systems should also leverage their own economic and political footprints as anchor institutions that source locally, pay a living wage, and foster trust with and invest in local communities. Leadership should prioritize workplace diversity and develop family-friendly workplace policies.

- As educators, we should include social and relational competency as a necessary qualification for future physicians. We support a holistic medical education process that relies on multi-modal assessments. We should develop curricula with SDOH learning objectives for every stage of physician education and evaluation. Undergraduate and graduate medical education should include experiential curricula for $\mathrm{SDOH}$ to not only make future physicians aware of how social and environmental circumstances outside the hospital are critical to health but also how to effectively advocate for improvement. We should ensure that accreditation and licensure examinations assess communication, cultural humility, bias and stereotyping behaviors, and structural competency. Medical and continuing education curricula should teach how structures - the large-scale organization of social, economic, and political power-impact health, ${ }^{10}$ with the goal of improving patient outcomes and care delivery, rather than learner test scores.

- As researchers, we should use science as a tool of inclusion by encouraging authentic partnerships with community members at all levels - involving patients and families in the design of social needs interventions and the prioritization of research questions, including community members in decision-making committees, and collaborating with community-based organizations in implementation. We should partner with researchers in other fields to identify interdisciplinary solutions to complex social problems that result in poor health. We should demand rigor in the evaluation of social interventions and policies to ensure that the best work moves forward.

- As advocates and as a professional society, we should advocate for the assessment of health impacts of key federal policies. We should advocate alongside public health and community partners to ensure the execution of the Affordable Care Act's Community Health Needs Assessments better align across the communities and neighborhoods we serve. ${ }^{11,} 12$ Finally, we should advocate to the federal and state governments to create financial structures that share dollars from all payer- and incentive-driven savings programs from healthcare and into other public sectors such as housing.

Across these spheres, science and ethics will be guiding principles. The scientific formation and testing of new ideas, interventions, and policies will be critical if we are to achieve real impact. The ethical principles of autonomy, beneficence, non-maleficence, and justice are all equally critical. Given history and existing power dynamics, the best intentions do not inoculate us from unintentional consequences. 


\section{ACTION ACROSS OUR SPHERES OF INFLUENCE}

\section{SGIM members, first and foremost, are} physicians and practice leaders. In these roles, we should create teams who support patients as people.

Engage in relationship-centered communication during patient visits. Primary care doctors and hospitalists should have holistic and strengths-based conversations with patients about social needs. ${ }^{13,14}$ Efforts to increase these kinds of discussions cannot be limited to pro-forma screening based solely on incentives to meet quality metrics or reimbursement bonuses. Relationship-centered communication includes empathetic conversations, shared decision-making, and appreciative inquiry, which includes asking patients about their "life stories" including childhood experiences, life milestones, and key relationships. This approach allows patients to feel "seen" as people, rather than as a list of problems or diagnoses. ${ }^{15,}{ }^{16}$ Including openended questions does not add length to the patient encounter ${ }^{17}$ and lays a foundation for a therapeutic alliance which can make clinical decision-making more efficient and effective. Employing a person-centric approach increases patient satisfaction and reduces physician burnout. ${ }^{17}$ Physicians must respect patient autonomy in approaching these conversations, explicitly identifying patient priorities and desire for healthcare system involvement in their social needs. Physicians should also engage in efforts to enhance self-awareness, including an examination of how their own background and life experiences influence their attitudes towards and interactions with patients from socially disadvantaged groups.

Embrace interprofessional team-based care. Identifying and addressing complex medical and social needs in a clinical setting requires a multidisciplinary care team. These teams should include members from across the healthcare and social care professions, including social workers, community health or peer navigators, nurses, pharmacists, mental health, and front-line or administrative support staff. Movement towards team-based approaches, where physicians can rely on colleagues with expertise in community-based and other social services, will reduce physician burden and increase the capacity of the care team to identify meaningful solutions for social needs. Building such team-based expertise can ensure that we provide tailored support addressing a range of our patients' social and behavioral needs to achieve health. ${ }^{18}$

\section{SGIM members are physician administrators and health system leaders. In these roles, we should partner with and support local communities.}

Buy instead of build community-based social services. While addressing social needs is somewhat new to healthcare, it is not new to community-based organizations that have long been providing needed services and supports. Health systems should avoid building de novo social care programs that can create unnecessary duplication of existing social services, often at a higher cost with less community input. We should reach out to existing community members and organizations for their expertise and partnership in social service delivery and community outreach. Dollars that should be supporting local communities, through such mechanisms as Community Needs Assessments and Community Benefits, often remain within the healthcare organizations, minimizing impact on community well-being. ${ }^{19}$

${ }^{21}$ We should ensure that our health systems partner with community members and organizations to ensure the flow of dollars to support existing services, such as after school programs, food banks, and homeless shelters. Physician leaders can be catalysts for community partnership, opening dialogue into how healthcare systems can listen to community members, and provide services and investments identified and prioritized by the communities they serve. As organizational leaders, these physicians can also establish and monitor metrics that measure progress toward agreed on areas of focus.

Leverage economic and political power to support communities. Healthcare organizations can intervene on upstream SDOH simply by redirecting how they spend their money and influence. "Anchor institutions" hire individuals from underserved communities, prioritize local and minority-owned vendors, create local financial investment strategies, hire a diverse workforce, institute family friendly policies, and pay employees a living wage. $^{22}$ The National Academy of Medicine's anchor institution approach to addressing $\mathrm{SDOH}$ has been endorsed by a growing collaborative of healthcare delivery organizations and can help health systems to take action. ${ }^{23,} 24$

Develop and nurture trust-based relationships with community institutions targeting health and health equity. Healthcare organizations should make institutional commitments to respectful practices for community engagement. ${ }^{25}$ Organizational leaders can and should establish systems and monitor adherence to these practices among all of the health professionals, faculty, learners, and administrators.

\section{SGIM members are educators who train future physicians across all medical specialties. In these roles, we should integrate multi-modal SDOH curricula and assessments throughout physician training and licensure.}

Prioritize humanism and empathy in medical school admissions. The medical school admissions process overemphasizes didactic achievement compared to 
interpersonal skills and emotional intelligence. We advocate for a holistic approach to medial school admissions to ensure that the pipeline of future doctors includes a diverse pool of candidates enriched with traits such as empathy, humility, and self-awareness. Increasing diversity in students and trainees will have significant positive long-term impacts on the culture of medicine, breaking down traditional doctor-patient hierarchies and improving patient care. ${ }^{26-28}$

Prioritize and institutionalize SDOH curricula in all aspects of medical education, including continuing medical education. We support critical service learning experiences as part of medical education curricula. Medical training must not only fulfill the classic core competencies (e.g., physiology, biostatistics) but also encompass structural competence, communication, relationship-centeredness, and cultural humility. These constructs are challenging to teach in a didactic format, which is why medical schools sometimes offer experiential "service learning," a pedagogical method in which students work in communities in order to expand their knowledge. Servicelearning - which often takes shape through projects such as free student-run clinics or health education fairs - can perpetuate health inequities and reinforce implicit biases if not thoughtfully designed. We should ensure that medical school and medicine residency curricula are informed by the notion of "critical service learning" wherein community members work alongside with students, rather than simply receiving services. ${ }^{10,29,30}$ Critical service-learning emphasizes dialogue with community members on the underlying causes of disparities. This dialogue is intended to build structural competency, which is an ability to understand illness as a downstream result of structural injustices and $\mathrm{SDOH}$. Examples of critical service learning rotations include experiential training with community-based organizations that address $\mathrm{SDOH}$ or a community health worker-led medical school rotation. ${ }^{31}$ For practicing physicians, CME should include $\mathrm{SDOH}$ competencies to ensure all physicians are aware of the scope of social and political impacts on $\mathrm{SDOH}$ for patients, how best to include social needs into routine patient care, and highlight provider implicit biases that perpetuate health inequalities. ${ }^{32}$

Revisit outcomes of interest for SDOH education and training. Moving away from strict didactic learning to more multi-modal or experiential learning requires innovative assessments. Accreditation and licensure bodies across the continuum of medical education (i.e., LCME, ACGME, and ACCME) should shift focus to patient outcomes as learners understand and incorporate SDOH in their clinical practice. In addition to including SDOH in UME, GME, and CME curricula, $\mathrm{SDOH}$ should be included in clinical skills assessments with a focus on impact in patient perceptions of care. We advocate for these changes in the USMLE as well and call upon the NBME to develop and implement meaningful assessments of SDOH within existing exams.

\section{SGIM members are scientists, grant reviewers, and leaders within research funding agencies. In these research roles, we should generate and promote interdisciplinary and community- engaged science. We should identify and use grading systems for social interventions to minimize evidence-to-practice gaps.}

Using rigorous scientific methods, built on the existing evidence to identify and test SDOH interventions. Researchers in medicine, nursing, public health, sociology, and economics have reached consensus that poverty impacts health across the life course. Currently, many SDOH "solutions" are being developed without evidence-based hypotheses or using scientific principles to identify and evaluate them. SDOH interventions and policies should be constructed with care, and build upon social and behavioral scientific disciplines now confronting structural inequality; social epidemiology, ${ }^{33}$ psychology, ${ }^{34}$ education, ${ }^{35}$ and economics, ${ }^{36}$ are replete with relevant theory and empirical evidence that should inform the development of new $\mathrm{SDOH}$ interventions. ${ }^{37}$

Revise research funding priorities to include interdisciplinary and community-focused research. Many researchers also serve as reviewers for federal and philanthropic grants. Most federal and philanthropic research funding focuses on disease-specific interventions or outcomes. This kind of research is designed to treat patients and not communities. As research reviewers, we can influence funding priorities and in so doing increase the workforce diversity of physician researchers by prioritizing innovative work focused on community health and health disparities. ${ }^{38}$ Increasing the diversity of researchers in the field, and increasing funding opportunities for communitybased research approaches, will increase the speed at which interventions are identified and tested and allow for new innovation from a previously underfunded group of researchers. Career development awards are particularly important to foster a generation of researchers with a deep understanding and commitment to reducing health disparities through community-engaged methods.

Science should be used as a tool of inclusion. Specific research methods that include community priorities and feedback are critical to ensure interventions and approaches to SDOH align with the communities and patients for whom they are designed. We advocate for approaches such as Participatory Action Research and Community-Based Participatory Research, ${ }^{39-41}$ which are designed to ensure that 
patients and families with lived experience are included at all stages of research including design, execution, participation, and dissemination. Outcomes of interest for our patients and families should be prioritized.

Identify and implement an evidence grading system. Currently, there are large evidence-to-practice gaps in the uptake of social interventions and policies. Many evidencebased effective interventions - such as nurse home visits for pregnant women, tailored support from community health workers, or housing coupled with intensive care management-remain underutilized. ${ }^{42-46}$ We support increased use of implementation science methods to increase the uptake and effectiveness of evidence-based practices for social interventions. We should use and build upon evidence grading systems such as the USPSTF, or Community Guide; these will ensure that investments have the greatest impact while highlighting knowledge gaps that can benefit from continued research. When causal inference is required, newer methods of randomization - pragmatic, adaptive, cross-over, and stepped wedge trials - which are used widely in global and public health, can help to ensure unbiased evaluation of social and community-based interventions. ${ }^{47-55}$ Because health-related social needs interventions are often complex and may be context-dependent, research should include mixed method designs that allow us to better understand why interventions have the results they do, and for whom, using qualitative methods.

\section{SGIM and its members are influential in evaluating and advocating for health-related policies. We should formally assess the health impacts of key policies and advocate for reg- ulations that redirect resources from health- care to other public sectors.}

As general internists, we are in a unique position to identify patterns that lead to poor health outcomes. Physicians should identify and call out the upstream policy and structural factors that impact our patients and the populations we serve and advocate for policy and structural changes. Adverse SDOH are a consequence of long-standing policies, cultures, and institutions derived from our nation's history of racism and exclusion. Therefore, direct policy action will have the most far-reaching impact on improving health, equity, and wellbeing. In our role as advocates, with more political capital than many other professionals, policy considerations should also align with our ethical and research-driven standards.

SGIM advocates for a "health in all policies" approach for federal, state, and local public and private sector policy. SGIM engages in legislative and advocacy priorities in line with our mission to create a just system of care in which all people can achieve optimal health. As a first step towards ensuring health in all policies, we propose the development of health impact assessments in policy-making. Health impact assessments will better ensure understanding of the intended and unintended health impacts of key federal policies. Similar to how the Congressional Budget Office (CBO) scores federal policy on its projected fiscal impact, we as physicians, who see and manage the downstream health consequences of many policies, advocate for a comparable health impact score. CBO or another federal agency can score proposed bills by estimating the population change in health-adjusted life expectancy. ${ }^{56,57}$ Healthcare comprises $18 \%$ of the GDP. ${ }^{58}$ Implementation of policies that worsen health, resulting in more healthcare spending and utilization that could otherwise be avoided, has significant ripple effects. SGIM should advocate with the CBO and the Centers for Medicare and Medicaid Services (CMS) to develop health impact assessment methodology and partner with experts in academic medicine, public health, epidemiology, and economics, to understand the intended and unintended health consequences of any new federal policy. Policy-makers should also first do no harm.

Services and supports for $\mathrm{SDOH}$ require appropriate funding and reimbursement. Currently, systems for financing SDOH are siloed and insufficient. Fee-for-servicebased funding strategies (paying for volume rather than value) need to be revised to incentivize health systems to invest in strategies to identify and engage with adverse SDOH facing the communities they serve. This should include increased focus and enforcement for community benefit plans by hospitals, an IRS requirement to maintain their tax-exempt status. Funding models should include sustainable and flexible reimbursement models to incentivize the use of interdisciplinary care teams, and to expand the impact of health systems by linking them with community-based resources. These changes require sufficiently resourcing primary care to build interprofessional, multidisciplinary teams with sufficient capacity and bandwidth to integrate health and social care. ${ }^{59}$

Public and private payers should develop payment methodologies that avoid the medicalization of $\mathrm{SDOH}$. Medicalization occurs when non-medical issues become defined and treated as medical problems. SDOH are structural and environmental circumstances that lead to downstream social risks that have direct health consequences. By incentivizing healthcare organizations and payers to engage in addressing SDOH, real dangers exist. If a private insurance company subsidizes housing, does this mean that our patient's home is now tied to their health plan? If their insurer denies certain medications or services, but they provide housing, how can an individual make a fair decision about medical care if it comes at the expense of losing their home? If insurers and healthcare organizations are building housing, or opening food banks, they are now positioned to limit access to only their 
patients, or only specific patient groups that demonstrate high enough costs. This raises profound ethical concerns.

\section{We advocate for policies to encourage large-scale investment in social services sectors. SDOH are intricately linked to} poverty. We advocate for anti-poverty policies at the local and federal level, including investment in housing and income supports. As specific social policies, these are evidence-based areas of investment to reduce the burden of poverty, decrease stress, and improve health outcomes for all. This is likely to require tough choices, redirecting some public funding from healthcare to these other sectors.

\section{SUMMARY}

SGIM recognizes the fundamental importance of social circumstances in health. ${ }^{60}$ As advances in the biomedical model have led to significant progress in the fight against disease, our commitment to understanding and addressing social drivers of health like those faced by our patient in the case study must be renewed. Physicians as advocates can influence change along a spectrum, from the individual patient encounter, teaching learners, our clinical practices, our organizational priorities, our research agendas and discoveries, our communities, and policy. SGIM acknowledges the importance of SDOH and will include SDOH considerations in all our organizational efforts and policies. We will encourage partnerships across disciplines for practice, organizational leadership, education, research, and advocacy. We will work intentionally to build community and interdisciplinary partnerships. The underpinnings of unjust distribution of SDOH will guide SGIM's work using ethical principles. We also encourage our general internist members to carry these considerations into their daily practice, their advocacy, their research portfolios, their organizations, and their teaching responsibilities and will develop tools to support them in this work.

Corresponding Author: Elena Byhoff, Department of Medicine, Institute for Clinical Research and Health Policy Studies Tufts Medical Center, Tufts University School of Medicine Boston, MA, USA (e-mail: ebyhoff@tuftsmedicalcenter.org).

Open Access This article is licensed under a Creative Commons Attribution 4.0 International License, which permits use, sharing, adaptation, distribution and reproduction in any medium or format, as long as you give appropriate credit to the original author(s) and the source, provide a link to the Creative Commons licence, and indicate if changes were made. The images or other third party material in this article are included in the article's Creative Commons licence, unless indicated otherwise in a credit line to the material. If material is not included in the article's Creative Commons licence and your intended use is not permitted by statutory regulation or exceeds the permitted use, you will need to obtain permission directly from the copyright holder. To view a copy of this licence, visit http://creativecommons. org/licenses/by/4.0/.

\section{REFERENCES}

1. Gee GC, Walsemann KM, Brondolo E. A life course perspective on how racism may be related to health inequities. Am $\mathrm{J}$ Public Health 2012;102(5):967-974.

2. Krieger N. Discrimination and health inequities. Int $J$ Health Serv 2014;44(4):643-710.

3. Castrucci B, Auerbach J. Meeting individual social needs falls short of addressing social determinants of health. Health Affairs Blog. 2019.

4. Braveman $\mathbf{P}$, Gottlieb $\mathbf{L}$. The social determinants of health: it's time to consider the causes of the causes. Public Health Rep. 2014;129(1_suppl2):19-31.

5. Alderwick H, Gottlieb LM. Meanings and misunderstandings: a social determinants of health lexicon for health care systems. The Milbank Quarterly. 2019;97(2).

6. Daniel H, Bornstein SS, Kane GC. Addressing social determinants to improve patient care and promote health equity: an American College of Physicians position paper. Ann Intern Med 2018; 168(8):577-578.

7. Kuo A, Wood DL, Duffee JH, Pasco J. Poverty and child health in the United States. Pediatrics. 2016;137(4):e20160339.

8. National Academies of Sciences E, Medicine. Integrating social care into the delivery of health care: moving upstream to improve the nation's health. National Academies Press; 2019.

9. Gotham KF. Racialization and the state: The Housing Act of 1934 and the creation of the Federal Housing Administration. Sociol Perspect 2000;43(2):291-317.

10. Metzl JM, Hansen H. Structural competency: Theorizing a new medical engagement with stigma and inequality. Soc Sci Med 2014;103:126-133.

11. Requirements for 501(c)(3) Hospitals Under the Affordable Care Act Section 501(r). https://www.irs.gov/charities-non-profits/charitableorganizations/requirements-for-501c3-hospitals-under-the-affordablecare-act-section-501r. Accessed Feb 12020.

12. Pennel CL, McLeroy KR, Burdine JN, Matarrita-Cascante D. Nonprofit hospitals' approach to community health needs assessment. Am J Public Health 2015;105(3):e103-e113.

13. Beach M, Inui T. the Relationship-Centered Care Research Network (Frankel, R., Hall, J., Haidet, P., Roter, D., Beckman, H., Cooper, LA, Miller, W., Mossbarger, D., Safran, D., Sluyter, D., Stein, H., \& Williamson, P.).(2006). Relationship-centered care: A constructive reframing. J Gen Intern Med.21:S3-S8.

14. Cooper LA, Beach MC, Johnson RL, Inui TS. Delving below the surface. J Gen Intern Med 2006;21(1):21-27.

15. Byhoff E, De Marchis EH, Hessler D, et al. Part II: a qualitative study of social risk screening acceptability in patients and caregivers. Am J Prev Med 2019;57(6):S38-S46.

16. Palakshappa D, Doupnik S, Vasan A, et al. Suburban families' experience with food insecurity screening in primary care practices. Pediatrics. 2017;140(1):e20170320.

17. Weiner JZ, McCloskey JK, Uratsu CS, Grant RW. Primary care physician stress driven by social and financial needs of complex patients. J Gen Intern Med 2019;34(6):818-819.

18. Viswanathan M, Kraschnewski JL, Nishikawa B, et al. Outcomes and costs of community health worker interventions: a systematic review. Med Care 2010:792-808.

19. Young GJ, Flaherty S, Zepeda ED, Singh SR, Rosen Cramer G. Community benefit spending by tax-exempt hospitals changed little after ACA. Health Aff 2018;37(1):121-124.

20. Singh SR, Young GJ, Daniel Lee S-Y, Song PH, Alexander JA. Analysis of hospital community benefit expenditures' alignment with community health needs: evidence from a national investigation of tax-exempt hospitals. Am J Public Health 2015;105(5):914-921.

21. Eckstein E, Hattis P. Hospital Investing in Health: Community Benefit in Massachusetts. Boston, MA: Community Catalyst; 2016.

22. Healthcare Anchor Network. https://healthcareanchor.network/. Accessed Mar 18, 2020.

23. Koh HK, Bantham A, Geller AC, et al. Anchor Institutions: Best Practices to Address Social Needs and Social Determinants of Health. Am J Public Health 2020;110(3):309-316.

24. Ubhayakar S, Capeless M, Owens R, Snorrason K, Zuckerman D. Anchor Mission Playbook. Chicago, IL: Rush University Medical Center. 2017.

25. Wesson DE, Lucey CR, Cooper LA. Building trust in health systems to eliminate health disparities. Jama. 2019;322(2):111-112.

26. Cooper L, Powe N. Disparities in patient experience, health care processes, and outcomes: The role of patient-provider racial, ethnic, 
and language concordance. Johns Hopkins University: The Commonwealth Fund; 2004.

27. LaVeist TA, Nuru-Jeter A, Jones KE. The association of doctor-patient race concordance with health services utilization. J Public Health Policy 2003;24(3-4):312-323.

28. Hardeman RR, Burgess D, Phelan S, Yeazel M, Nelson D, van Ryn M. Medical student socio-demographic characteristics and attitudes toward patient centered care: Do race, socioeconomic status and gender matter? A report from the Medical Student CHANGES study. Patient Educ Couns 2015;98(3):350-355.

29. Mitchell TD. Traditional vs. critical service-learning: Engaging the literature to differentiate two models. Michigan J Commun Service Learn 2008; 14(2):50-65

30. Marullo S, Edwards B. From charity to justice: The potential of university-community collaboration for social change. Am Behav Sci 2000;43(5):895-912.

31. Kangovi S, Carter T, Smith RA, DeLisser HM. A community health worker-led rotation to train medical students in the social determinants of health. J Health Care Poor Underserved 2018;29(2):581-590.

32. Chapman EN, Kaatz A, Carnes M. Physicians and implicit bias: how doctors may unwittingly perpetuate health care disparities. J Gen Intern Med 2013:28(11):1504-1510.

33. Du Bois WB. The study of the Negro problems. The Ann Am Acad Polit Social Sci 1898:1-23.

34. Adelman C. Kurt Lewin and the origins of action research. Educ Action Res 1993;1(1):7-24.

35. Freire P. Pedagogy of the oppressed (revised). New York: Continuum 1996.

36. Banerjee AV, Banerjee A, Duflo E. Poor economics: A radical rethinking of the way to fight global poverty. Public Affairs; 2011.

37. Charon R. Narrative medicine: a model for empathy, reflection, profes sion, and trust. Jama. 2001;286(15):1897-1902.

38. Hoppe TA, Litovitz A, Willis KA, et al. Topic choice contributes to the lower rate of $\mathrm{NIH}$ awards to African-American/black scientists. Sci Adv. 2019;5(10):eaaw7238

39. Coombe CM, Schulz AJ, Brakefield-Caldwell W, et al. Applying Experiential Action Learning Pedagogy to an Intensive Course to Enhance Capacity to Conduct Community-Based Participatory Research. Pedagogy Health Promotion 2019:2373379919885975.

40. Israel BA, Coombe CM, Cheezum RR, et al. Community-based participatory research: a capacity-building approach for policy advocacy aimed at eliminating health disparities. Am $J$ Public Health 2010;100(11):2094-2102

41. Cashman SB, Adeky S, Allen III AJ, et al. The power and the promise: working with communities to analyze data, interpret findings, and get to outcomes. Am J Public Health 2008;98(8):1407-1417.

42. Sadowski LS, Kee RA, VanderWeele TJ, Buchanan D. Effect of a housing and case management program on emergency department visits and hospitalizations among chronically ill homeless adults: a randomized trial. Jama. 2009;301(17):1771-1778.

43. Counsell SR, Callahan CM, Clark DO, et al. Geriatric care management for low-income seniors: a randomized controlled trial. Jama 2007;298(22):2623-2633.

44. Louis MES, Morse DL, Potter ME, et al. The emergence of grade A eggs as a major source of Salmonella enteritidis infections: new implications for the control of salmonellosis. Jama. 1988;259(14):2103-2107.
45. Olds DL, Kitzman H, Knudtson MD, Anson E, Smith JA, Cole R. Effect of home visiting by nurses on maternal and child mortality: results of a 2decade follow-up of a randomized clinical trial. JAMA Pediatr 2014;168(9):800-806

46. Kangovi S, Mitra N, Grande D, Huo H, Smith RA, Long JA. Community health worker support for disadvantaged patients with multiple chronic diseases: a randomized clinical trial. Am J Public Health 2017;107(10):1660-1667.

47. Irving $\mathbf{E}$, van den Bor $\mathbf{R}$, Welsing $\mathbf{P}$, et al. Series: Pragmatic trials and real world evidence: Paper 7. Safety, quality and monitoring. J Clin Epidemiol 2017;91:6-12.

48. Kalkman S, van Thiel GJ, Zuidgeest MG, et al. Series: Pragmatic trials and real world evidence: Paper 4. Informed consent. J Clin Epidemiol 2017;89:181-187.

49. Meinecke A-K, Welsing $\mathbf{P}$, Kafatos G, et al. Series: pragmatic trials and real world evidence: Paper 8. Data collection and management. J Clin Epidemiol 2017;91:13-22.

50. Rengerink KO, Kalkman S, Collier S, et al. Series: Pragmatic trials and real world evidence: Paper 3. Patient selection challenges and consequences. J Clin Epidemiol 2017;89:173-180.

51. Welsing PM, Rengerink KO, Collier S, et al. Series: Pragmatic trials and real world evidence: Paper 6. Outcome measures in the real world. J Clin Epidemiol 2017;90:99-107.

52. Worsley SD, Rengerink KO, Irving E, et al. Series: Pragmatic trials and real world evidence: Paper 2. Setting, sites, and investigator selection. J Clin Epidemiol 2017;88:14-20.

53. Zuidgeest MG, Goetz I, Groenwold RH, et al. Series: Pragmatic trials and real world evidence: Paper 1. Introduction. J Clin Epidemiol 2017;88:7-13

54. Zuidgeest MG, Welsing PM, van Thiel GJ, et al. Series: Pragmatic trials and real world evidence: Paper 5. Usual care and real life comparators. J Clin Epidemiol 2017;90:92-98.

55. Binik A. Delaying and withholding interventions: ethics and the stepped wedge trial. J Med Ethics 2019;45(10):662-667.

56. Ranabhat CL, Atkinson J, Park M-B, Kim C-B, Jakovljevic M. The influence of universal health coverage on life expectancy at birth (LEAB) and healthy life expectancy (HALE): a multi-country cross-sectiona study. Front Pharmacol 2018;9:960.

57. Kassebaum NJ, Arora M, Barber RM, et al. Global, regional, and national disability-adjusted life-years (DALYs) for 315 diseases and injuries and healthy life expectancy (HALE), 1990-2015: a systematic analysis for the Global Burden of Disease Study 2015. Lancet 2016;388(10053):1603-1658.

58. Health Care. https://www.cbo.gov/topics/health-care. Accessed Feb 1, 2020

59. Implementing High-Quality Primary Care. Accessed Mar 3, 2020

60. Link BG, Phelan J. Social conditions as fundamental causes of disease. J Health Soc Behav 1995:80-94.

Publisher's Note: Springer Nature remains neutral with regard to jurisdictional claims in published maps and institutional affiliations. 